cyclosporin rinse (swish and spit) proved helpful without causing systemic side effects and offered the prospect of longer remissions. ${ }^{17}$ Finally, in recalcitrant cases treatment with oral psoralens and ultraviolet A (PUVA) may be considered, though it may confer that most absurd of all status symbols, a genuine tan inside the mouth. ${ }^{18}$ Erasmus Wilson would have been glad to hear of these developments, but sorry that the cause of his disease is still not known.

Consultant Dermatologist,

J A SAVIN

Royal Infirmary,

Edinburgh EH3 9YW

I Samman PD). L ichen planus: a detcrmatological centenary Br f Dermulul 1969:81:306-7.

2 Ramsay DI, Fox AB. The ability of primary care physicians to recognise the common dermatoses. Arch Dermatol 1981;117:620-2.

3 Johnson M-L.T, Roberts J. Skin conditions and related need for medical care among persons 1-74 years. Hyattsville: US Department of Health Education, 1978. (DHEW Publication No (PHS) 79-1660.)

4 Salonen $\mathrm{L}$, Axell $\mathrm{T}$, Hellden L. Occurrence of oral mucosal lesions, the influence of tobacco habit and an estimate of treatment time in an adult Swedish population. $f$ ( Oral l'athol Med 1990;19:170-6

5 Thorn JJ, Holmstrup P', Rindum J, Pindborg JJ. Course of various clinical forms of lichen planus: a prospective follow-up. 7 Oral P'athol 1988;17:213-8.
6 Holmstrup P, Thorn JJ. Malignant development of lichen planus--affected oral mucosa. f ()ral l'athol 1988:17:219-25.

Hampl BC, Malmstron MJ, Aalherg VA, Hannula JA, Vikkula J. Psychiatric disturbance in patients with oral lichen planus. ()ral Surg ()ral Med ()ral l'athol 1987;63:429-32.

8 Potts C., Hamberger J, Scully $C$. The medication of patients with oral lichen planus and the association of non-steroidal anti-inflammatory drugs with crosive lesions. ()ral Surg ()ral Med assiciation of non-steroidal
Oral l'athol 1987; 64:541-3.

9 Lund $\mathrm{PO}$, Hurlen B, L.yberg T, Aas F. Amalgam related oral lichenoid reaction. Scand 7 Dent Res $1986 ; 94: 448-51$

10 James J, Ferguson MM. Oral lichenoid reactions related to mercury sensitivity. Br f Oral Maxillofac Surg 1987;25:474-86.

11 Gariceh J, Fodd PJ, Lewis M, Forsyth A, Rademaker M. The significance of a positive patch test to mercury in oral discase. Br. I Dermatol 1990);123 (suppl 37):25-6.

12 Holmstrup P, Schiot\% AW, Westergaard J. Effects of dental plaque control in gingival lichen planus. ()ral Surg ()ral Med (Oral Pathol 1990;63:585-90).

13 Silverman S, (jorsky M, Lozada-Nur E. A prospective follow-up of 570 patients with oral lichen planus. Persistence, remission and malignant assocation. ()ral Surg ()ral Med ()ral l'athol 1985;60:30)-4

14 Deasy PB, Collins AEM, Burke FM, Shanley DB. In vitro and in vivo cvaluation of a bondable compact for the prolonged delivery of triamcinolone acetonide to the oral cavity in patients with lichen planus. Pharm Acta Helv 1989;64:276-9.

15 Plemons JM, Rees TI), Zacharin NY Absorption of a topical steroid and evaluation of adrenal suppression in patients with erosive lichen planus. (Yral Surg ()ral Med Oral P'athol 1990;69: $688-93$.

16 (Giustina TA, Stewart JCB, Ellis CN, et al. Topical application of isotretinoin gel improves oral lichen planus. Arch Dermatol 1986;122:534-6.

17 Eisen 1), Eillis CN, Duell EA, (iriffiths CEM, Voorhees JJ. Effiect of topical cyclosporin rinse on oral lichen planus. N Eingl I Med 1990;323:290-4

18 Jansen C'T, Lehtinen R, Happonen RP', Lehtinen A, Soderlund K. Mouth PUVA; a new treatment for recalcitrant oral lichen planus. Photodermutol 1987;4:165-6.

\title{
Infantile colitis
}

\section{Allergy to food is the main non-infective cause and is easily treatable}

Infancy is one of the two periods of childhood in which colitis may present, the second being in late childhood and early adolescence.' The obvious symptom in affected infants is chronic bloody diarrhoea in the first few weeks or months of life. Our ability to diagnose the cause of infantile colitis has recently improved considerably with the arrival of small calibre fibreoptic colonoscopes. These allow the infant's colon to be visualised and multiple histological specimens to be obtained.

The most common cause is infection-at least 2500 cases were reported nationally in 1989 (J Cowden, Communicable Disease Surveillance Centre, personal communication). In Britain the pathogens seen most often are Campylobacter jejuni, ${ }^{2}$ Salmonella spp, Shigella spp, enterotoxigenic Escherichia coli, which produces a Shiga-like toxin, verotoxin, ${ }^{3}$ and Clostridium difficile. The course of colonic infections in infancy may be more severe and prolonged than in adults because the immune system is still developing, and certain organisms that do not usually cause a colitis may do so in small babies. For example, Yersinia enterocolitica,${ }^{+}$Cryptosporidium, ${ }^{5}$ Aeromonas hydrophilia, ${ }^{\circ}$ and Clostridium difficile may be associated with colitis even without antecedent treatment with antibiotics. ${ }^{7 x}$

When no infectious agent is detectable the colitis may have a more serious prognosis. Classic inflammatory bowel disease may present at any age, and Crohn's disease is more common than ulcerative colitis in children in Britain." It now seems that the peak in incidence of colitis in infancy is not due to classic inflammatory bowel disease but is attributable to colitis due to food allergy." "In one study of non-infectious colitis in infancy all eight patients had an allergic colitis ${ }^{10}$; in another two of five children under 1 year of age were similarly afflicted, the three others having indeterminate colitidesinflammation with no diagnostic features." The less common causes include colitis with coeliac disease ${ }^{1213}$ and two newly described conditions, autoimmune enteropathy with colitis ${ }^{1+}$ and a familial necrotising enterocolitis (J A Walker-Smith, personal communication). ${ }^{\text {' }}$
Allergic colitis is a disorder related to atopy which occurs in association with the ingestion of specific dietary antigens, usually in cows' milk or soya based formula feeds, or, if the infant is breast fed, with antigens ingested by the mother which have passed into her milk. Although it first presents in early infancy, symptoms may recur when new antigens are encountered on weaning: wheat, soya, beef, pork, fish, and goats' milk have all been implicated. ${ }^{16}$

The macroscopic features seen at colonoscopy in infants with colitis are often distinctive. Allergic colitis has a characteristic patchy appearance with areas of inflammation (without ulceration) separated by intervening normal mucosa. Crohn's disease and familial necrotising enterocolitis may also appear patchy, but usually there is ulceration-aphthous ulcers and snail track ulcers in Crohn's disease and deep "punched out" ulcers in familial necrotising enterocolitis. ${ }^{15}$ Inflammation is diffuse in ulcerative colitis and autoimmune colitis (usually affecting the colon with similar severity throughout $\left.{ }^{14}\right)$. These clear cut findings and the ability provided by colonoscopy for multiple biopsies throughout the colon have made precise diagnosis possible in most infants with colitis. Nevertheless, while the histological features of classic inflammatory bowel disease are well known, ${ }^{17}$ those of allergic colitis are not. The key feature is the infiltrate of the lamina propria, which consists largely of eosinophils (which clump together and invade the epithelium) and plasma cells. ${ }^{10}$

In infancy - as in later life-the non-infective infantile colitides run a chronic fluctuating course which may result in both mortality and severe morbidity if not controlled. The treatment of classic inflammatory bowel disease, autoimmune disease, and familial necrotising enterocolitis is - as in older children and adults - with anti-inflammatory and immunosuppressive drugs and surgery.

In colitis due to food allergy, removal of offending foods from the diet (usually from two to five foods in an individual patient) will result in the relief of symptoms, and biopsies will show a fall in the numbers of eosinophils and plasma cells bearing IgE." Treatment need be only temporary as patients 
recover with time, gaining tolerance of previously offending foods. The foods can then be reintroduced. The timing of this tolerance is variable, ranging from about 18 months to 8 years of age ${ }^{16}$ and different foods may often be tolerated at different ages in one subject. All children studied to date have successfully been reintroduced to virtually all excluded foods without symptoms recurring.

Non-infective colitis in children under 1 year of age seems, then, to be predominantly allergic in origin and to follow a similar course to other disorders related to atopy. Parents may be reassured that their children will "grow out of it" and that classic inflammatory bowel disease does not develop later. The serious colonic inflammatory diseases do occur in infancy, however, and infants with bloody diarrhoea require full investigation and a precise diagnosis to be made before treatment is started.

SUSAN M HILL Clinical Research Fellow PETER J MILLA Senior Lecturer in Child Health

Department of Child Health, Institute of Child Health, London WC1N 1EH
1 Nixon $\mathrm{HH}$, Krebs C. Inflammatory bowel disease in children: presentation and diagnosis. Entzunderliche Darmerkrankanger im Kindesalten: Symptomatik und Diagnose. $Z$ Kinderchi 1983;38:387-91.

2 Guandalini S, Cucchiara S, de Ritis G, et al. Campylobacter colitis in infants. F Pediatr 1983;102:72. 4.

Karmali M. Infection by verocytotoxin-producing Escherichia coli. Clin Microbiol Rev 1989;2:15-

Brown R, Tedesco FJ, Assad RT, Rao R. Yersinia colitis masquerading as pseudomembranous colitis. Dig Dis Sci 1986;31:548-51.

Hart $\mathrm{MH}$, Kruger R, Nielsen S, Kaufman S. Acute self-limited colitis associated with Cryptosporidium in an immunocompetent patient. $\mathcal{F}$ Pediatr Gastroenterol Nutr 1989;8:401-3.

6 Marsik F, Werlin SL. Aeromonas hydrophila colitis in a child. 7 Pediatr Gastroenterol Nur 1984;3:808-11.

7 Adler SP, Chandrika T, Berman WF. Clostridium difficile associated with pseudomembranous colitis: occurrence in a 12 week old infant without prior antibiotic therapy. Am f Dis Child 1981;135:820-2.

8 Delmee M, Verellen G, Avesani V, Francois G. Clostridium difficile in neonates: serogrouping and epidemiology. Eur F Pediatr 1988;147:36-40.

9 Booth IW, Grand RJ. Chronic inflammatory bowel disease. In: Milla PJ, Muller DPR, eds. Harries' paediatric gastroenterology. London: Churchill Livingstone, 1988:137-67.

10 Jenkins HR, Pincott JR, Soothill JF, Milla PJ, Harries JT. Food allergy; the major cause of infantile colitis. Arch Dis Child 1984;59:326-9.

1 Chong SKF, Blackshaw AJ, Morson BC, Williams CB, Walker-Smith JA. Prospective study of colitis in infancy and early childhood. F Pediatr Gastroenterol Nutr 1986;5:352-8.

12 Breen EG, Coughlan G, Connolly CE, Stevens FM, McCarthy CF. Coeliac proctitis. Scand $\mathcal{f}$ Gastroenterol 1987;22:471-7.

13 Ansaldi N, Santini B, Dell'Olio D, Levis F. Proctosigmoiditis and coeliac disease. Arch Dis Child 1978;53:645-8.

14 Hill SM, Milla PJ, Bottazzo GF, Mirakian R. Autoimmune enteropathy and colitis: is there a generalised autoimmune gut disorder? Gut 1991;32:36-42.

15 Chong SK, Wright VM, Nishigame T, et al. Infantile colitis: a manifestation of intestinal Behcet's syndrome. F Pediatr Gastroenterol Nutr 1988;7:622-7.

16 Hill SM, Milla PJ. Infantile food allergic colitis. Arch Dis Child 1990;65:132-3.

17 Macdermott RO, Stenson WF. Alterations of the immune system in ulcerative colitis and Crohn's disease. In: Dixon FJ, ed. Advances in immunology. New York: Academic Press, 1988:285-326.

\title{
Chemoprophylaxis for Haemophilus influenzae type b
}

\author{
Rifampicin should be given to close contacts
}

Capsulated Haemophilus influenzae type b causes meningitis, bacteraemia, epiglottitis, and a range of other invasive diseases, mainly in young children. ${ }^{1}$ Laboratory reports of cases of invasive $H$ influenzae disease increased from 869 in 1983 to 1259 in 1989 in England and Wales (Communicable Disease Surveillance Centre, unpublished data), though the true incidence may be higher. ${ }^{2}$ Secondary cases, although rare, are important because they are potentially preventable.

At any one time about $1 \%$ of children aged under 6 years are colonised with $H$ influenzae type b, generally in the nasopharynx. ${ }^{3}$ Carriage rates are higher in household and other contacts of children with established infection, ${ }^{45}$ and surveys in the United States have shown an increased risk of Haemophilus influenzae type b disease in these contacts. ${ }^{6-11}$ The risk is highest in household contacts aged under 2 years $(3 \cdot 3 \%$ over 30 days) and declines with increasing age: for children aged under 6 years the relative risk is up to 800 times greater than the background level of disease. ${ }^{6812}$ For other contacts most information is derived from American day care centres. Rates of secondary disease vary considerably, ${ }^{11}{ }^{13-16}$ but combining the studies gives a risk of about $1 \%$ over 60 days for untreated classroom contacts aged under 2 years -25 times higher than the background level. ${ }^{1}$

Rifampicin $20 \mathrm{mg} / \mathrm{kg}$ in a single daily dose for four days eliminates $H$ influenzae type $\mathrm{b}$ from the nasopharynx in about $95 \%$ of cases. ${ }^{18}$ Elimination of $H$ influenzae type b does not, however, necessarily equate with prevention of secondary disease. In the only prospective trial of rifampicin versus placebo in household contacts there were three secondary cases among 125 children aged under 4 years who received placebo and none in 95 who received rifampicin. ${ }^{11}$ Among children aged under 4 attending day care centres in the same study, a single case occurred in 91 who received placebo compared with no cases in 208 given rifampicin. Follow up was for 30 days.

Other studies in day care centres have shown a reduction in the incidence of secondary disease over 60 days after rifampicin prophylaxis, ${ }^{1316}$ though failure of prophylaxis has been reported in both household ${ }^{19}$ and day centre contacts. ${ }^{2021}$ Even if administered with perfect efficiency rifampicin prophylaxis would prevent only $1 \cdot 2 \%$ of cases in the United States. ${ }^{11}$

Surveillance of contacts beyond 60 days has not been undertaken, though the risk period is probably much longer, ${ }^{6}$ especially when rifampicin is used. ${ }^{13}$ After nasopharyngeal $H$ influenzae type $\mathrm{b}$ has been eradicated from the target population susceptible contacts may slowly become recolonised and late secondary cases may then occur. Susceptibility may be reduced in the interval, however, by exposure to non-pathogenic haemophili or cross reacting Escherichia coli $i^{22}$ or by immunisation with conjugated vaccines when these become available. Second episodes of invasive disease also occur occasionally, ${ }^{23-25}$ and it has been proposed that rifampicin in addition to primary antibiotics might prevent some of these episodes, though failures have been recorded. ${ }^{26}$

No placebo controlled studies of the influence of antibiotics on secondary attack rates in household, nursery, or playgroup contacts will have been completed in Britain before an effective vaccine is introduced. A policy on chemoprophylaxis therefore has to be established on the basis of American experience, although the data may not be comparable.

The grounds for giving rifampicin prophylaxis to household contacts seem strong. Those for giving it to contacts in playgroups, nurseries, and creches are less clear because the risk of disease is much lower, antibiotics would have to be offered to many more people, and the evidence for protection is weaker. Rifampicin is relatively safe and it reduces secondary attack rates in household contacts for at least 30 days. Other antibiotics-for example, ciprofloxacin-may also work but have not been assessed. Adverse effects of rifampicin include interference with oral contraception and red coloration of urine, sputum, and tears. The Family 